\title{
CLINICAL CHARACTERISTICS AND KINESITHERAPY TREATMENT OF CONGENITAL TORTICOLLIS MUSCULAR
}

\author{
ZHERALLDIN DURGUTI, ARDIANA MURTEZANI, EQREM GARA*, TEUTA DURGUTI
}

Physical Medicine and Rehabilitation Clinic, University of Pristina, Kosovo. Email: eqremgara3@gmail.com

Received: 20 May 2017, Revised and Accepted: 29 June 2017

ABSTRACT

Objective: Torticollis is a deformity characterized by the lateral flexion of the head to the arm on the side of the localization of deformity and its rotation on the opposite side. The aim of this paper is to identify the clinical characteristics that have an impact on the progression of the congenital muscular cramping, as well as to show the role of kinesitherapy in the treatment of torticollis.

Methods: The research was conducted in the "Therapy" - Physical Therapy Clinic in Pristina, in the 2-year period since February 2014 until 2016. The total number of infants diagnosed with torticollis is 160 , ranging from 0 to 9 months. At the beginning of the research, the examinations of all infants were performed, all the necessary tests, measurements, and motor functions. Afterward, they were rehabilitated for 3 consecutive weeks with 5 sessions per week, a total of 15 sessions for each. After the rehabilitation was completed, over again, the same tests were made as it was done in the beginning. Questionnaires were completed on the first and last visit for all infants.

Results: In the first visit of the infants' examination, there was no significant difference between the groups (Chi-test $=0.96, p=0.1$ ), whereas in the second examination, after 15 rehabilitation sessions, there was a significant difference in improvement of all the treated groups with kinesiotherapy. Significant result was achieved in mobility where at the beginning of the treatment, there was a very large limitation of neck mobility (different mean $=-31.0 \pm 10.0 .95 \%$ CI: 33.7--28.2, p<0.001). A small limitation of mobility remained only among some third-degree infants in the 6-9 month age group because of the time appearance for physical treatment was delayed (different mean $=-27.8 \pm 12.6,95 \%, \mathrm{CI}: 31.2--24.4, \mathrm{p}<0.001$ ).

Conclusion: From the results of our research on kinesiotherapy with infant toddlers with torticollis, we conclude that kinesitherapy has a primary and very successful effect on the treatment of babies with muscular torticollis.

Keywords: Torticollis, Kinesitherapy, Infants, Clinical features, Neck mobility.

(c) 2017 The Authors. Published by Innovare Academic Sciences Pvt Ltd. This is an open access article under the CC BY license (http://creativecommons. org/licenses/by/4. 0/) DOI: http://dx.doi.org/10.22159/ajpcr.2017.v10i8.20085

\section{INTRODUCTION}

Torticollis is a deformity characterized by the lateral flexion of the head to the arm on the side of the localization of the deformity and its rotation on the opposite side [1]. Congenital muscular torticollis by the frequency is the third deformity in the children's orthopedics, following the developmental disorder of the skeletal and congenital equinox [2]. It is a unilateral consequence of the sternocleidomastoid muscle contractility (MSCM) [3]. Observation and physical therapy, with or without ortho, is in the most of the cases an effective treatment, especially if it is done within the first year of life [4]. Usually, it is associated with facial and head asymmetry and with the amplitude movement limitation of the cervical pillar [5].

Regarding the etiology of torticollis is still unclear, but many different authors think that the presentation of congenital musculoskeletal neoplasm in babies has to do with polyethiology factors, such as fetal position in the uterus, limited space inside the uterus, rotation of the baby's head during baby birth, positioning, and manipulation of the baby after birth, and in some cases, genetic factors may also be affected $[6,7]$.

Diagnosis is done on the basis of a clinical examination of the cervical region, where the cervical axis radiography is necessary to exclude bone modifications, as well as examining otorhinolaryngology and ophthalmology are necessary too $[8,9]$. Meanwhile, the clinical signs of torticollis are characterized based on the position of babies head. The head of the baby is humble on the sick side, there is movement restriction on that side, and muscle tone is increased, while MSCM is short and strong [10].
For the physical treatment of torticollis, these procedures are applied: Thermotherapy, electrotherapy, kinesitherapy, and work therapy, which are functional orthopedic aids [11,12]. The primary role in treatment is kinesitherapy, which is used to prolong MSCM extension and strengthening of other structures around the neck, as well as eliminating the muscular contraction [13].

In most of the cases, the problems of infants with torticollis with the application of physical therapy are cured. In rare cases, surgical intervention is needed, which it comes due to the non-presentation of the infant's baby with torticollis for physical treatment because it is much more effective to treat infants when it begins in the early days of the baby's birth $[14,15]$.

The main purpose of this paper is to identify the clinical characteristics that have an impact on the progression of congenital muscular cramping and to show the role of the kinesitherapy in the infant's cramping/ torticollis treatment.

\section{METHODS}

Due to the realization of this prospective paperwork, partial research methods were conducted through a questionnaire obtained by Anna Marie Ohmman PT.MSC.PHD at Queen Silvia Children's Hospital "Questionnaire for torticollis in infants," which includes general patient data, patient examination, as well as the achieved results at the end of the treatment [16].

The research was conducted in the "Therapy"- Physical Therapy Clinic in Pristina in the 2-year period since February 2014 until 2016. The 
total number of infants diagnosed with torticollis is 160, ranging from 0 to 9 months. The babies involved in the research were divided into three groups by age and number of sessions applied. The first group included 53 infants (33.13\%), in the second group 52 infants (32.5\%), and the third group included 55 infants (34.38\%).

At the beginning of the research, all of the infant's examinations were made, all the necessary tests, measurements, and motor function. Afterward, they were rehabilitated for 3 consecutive weeks with 5 sessions per week, in total 15 sessions per each. After the rehabilitation was completed, over again, the same tests were made as it was done in the beginning. In the first and last visit, the questionnaires were completed for all infants. All parents were informed and agreed on the manner and the purpose of the research.

Throughout the clinical examination cervical spine mobility was examined, cervical spine muscle force, the shape of head and face was assessed and also the presence of concomitant anomalies.

The criteria for introducing infants were between 0 and 9 months, a diagnosis with torticollis set by the pediatrician, orthopedics, and physiatrist, as well as the infants with good health in general, verified with anamnesis and clinical examination. Whereas those infants who have not been treated in time have been diagnosed with torticollis as a result of other pathologies who have been surgically treated - the tenotomy is not included in the research.

The presentation of data is done through tables and graphs while data processing is done with the SPSS program. As regarded to statistical parameters structure index was calculated, arithmetic average, standard deviation (SD), minimal and maximal values. The data were tested by t-test and the verification of the tests was done for the confidence or credibility level 95\% and 99\%, respectively, $\mathrm{p}<0.05$ and $\mathrm{p}<0.01$.

\section{RESULTS}

Table 1 lists the demographic data and the clinical features of 160 infants involved in the research. There was no significant difference according to the treated groups, which means that the three of the groups were the same for the number included in the study (Chi-test=0.96, $\mathrm{p}=0.1$ ). Out of 160 infants, 87 (56\%) were girls while 73 (44\%) were boys with an imprecise distinction $\mathrm{p}=0.27$. The average weight of babies in the study was $3218.3 \mathrm{~g}$. Of the 160 examined babies, 95 (59.4\%) are of natural origin while $65(40.6 \%)$ are of caesarean origin.

The largest number of the cases were at the first-born child ( 74 or $46.3 \%$ ), followed by second-born children ( 67 or $41.9 \%$ ), and the lowest number of cases were on the third child born in the order of 19 or $11.9 \%$. On the total number of babies, 93 or $(58.1 \%)$ of the cases had facial asymmetry while 67 (41.9\%) had no facial asymmetry. From the 160 babies involved in the paperwork, 94 babies or (58.8\%) had regular head shape whereas 66 babies or (41.3\%) had irregular head form. In 8 babies or $(5 \%)$ of them, there was present the tumefaction while in 152 or $(95 \%)$ of cases, we did not conclude the tumefact in the muscle region.

In Fig. 1 data on the other abnormal infants were reported, wherefrom 118 , out of the total number of babies (73.8\%) have no other accompanying abnormalities; 13 or $(8.1 \%)$ cases had subluxatio coxae, 12 cases or $(7.5 \%)$ had brachial plexus injury, and 11 of the cases or $(6.9 \%)$ had coxae dysplasia.

Table 2 shows the data for the average improvement of lateral anesthesia where we reached the highest level in the 0-3 months of the infants in groups(different mean $=-31.0 \pm 10.0,95 \%$, CI: 33.7 up to $-28.2, \mathrm{p}<0.001$ ), and then, in the group ages 3.1-6 months (different mean $=-29.3 \pm 8.7,95 \%, \mathrm{CI}: 31.7-26.9, \mathrm{p}<0.001$ ) whereas the lowest improvement in the group age is 6.1-9 months (different mean = $-27.8 \pm 12.6,95 \%$, CI: 31.2--24.4, p<0.001).
Table 1: Demographic data and clinical characteristics of the infants

\begin{tabular}{ll}
\hline $\begin{array}{l}\text { Baseline demographic and clinical } \\
\text { characteristics }\end{array}$ & Total n=160 (\%) \\
\hline Gender & \\
Girls & $87(54.38)$ \\
Boys & $73(45.63)$ \\
Body weight & $53(33.13)$ \\
2500-3000 & $82(51.25)$ \\
3001-3500 & $16(10.00)$ \\
3501-4000 & $9(5.63)$ \\
4001-4500 & \\
Way of birth & $95(59.40)$ \\
Natural birth & $65(40.60)$ \\
Caesarean birth & $74(46.30)$ \\
Line of the infant born & $67(41.90)$ \\
First & $19(11.90)$ \\
Second & \\
Third & $93(58.10)$ \\
Facial symmetry & $67(41.90)$ \\
Asymmetric & \\
Symmetric & $94(58.80)$ \\
Shape of head & $66(41.30)$ \\
Regular & $8(5.00)$ \\
Irregular & $152(95.00)$ \\
Tumefaction & \\
Yes & \\
No & \\
\hline
\end{tabular}

Table 2: Improvement of lateral anion by comparative groups

\begin{tabular}{llllll}
\hline \multirow{2}{*}{$\begin{array}{l}\text { Age } \\
\text { group }\end{array}$} & \multicolumn{2}{l}{ Mean \pm SD } & & \multirow{2}{*}{ SE } & 95\% CI \\
\cline { 2 - 4 } & Before & After & Different & & \\
\hline $1-3 \mathrm{~m}$ & $58.0 \pm 9.7$ & $88.9 \pm 3.0$ & $-31.0 \pm 10.0$ & 1.4 & $-33.7--28.2$ \\
$3.1-6 \mathrm{~m}$ & $60.0 \pm 9.7$ & $89.3 \pm 2.4$ & $-29.3 \pm 8.7$ & 1.2 & $-31.7--26.9$ \\
$6.1-9 \mathrm{~m}$ & $62.2 \pm 12.6$ & $90.0 \pm 0.0$ & $-27.8 \pm 12.6$ & 1.7 & $-31.2--24.4$ \\
Total & $60.1 \pm 10.9$ & $89.4 \pm 2.2$ & $-29.3 \pm 10.6$ & 0.8 & $-31.0--27.7$ \\
\hline
\end{tabular}

SD: Standard deviation

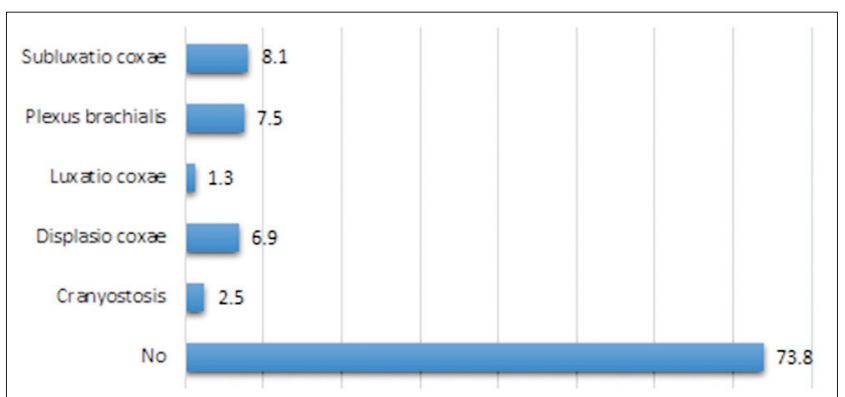

Fig. 1: Concomitant abnormalities among infants with torticollis

Table 3 shows that the results of the examinations that were made at the end of the treatment according to the number of sessions applied. The first group of the (infants from 0 to 3 months) was needed only 15 sessions for their full treatment because the timing of their appearance in the therapy was earlier, so the result was better and faster. The second group (infants from 3 to 6 months) needed 30 therapeutic sessions. The third group (babies aged from 6 to 9 months) needed 45 therapeutic sessions for achieving normal amplitude of the neck mobility because of the appearance for physical treatment was delayed, so the treatment lasted longer than to the first and second group. 
Table 3: Number and percentage of infants at the end of the treatment according to the number of applied sessions

\begin{tabular}{ll}
\hline Number sessions & Total (\%) \\
\hline 45 & $63(39.4)$ \\
30 & $44(27.5)$ \\
15 & $53(33.1)$ \\
Total & $160(100.0)$ \\
\hline
\end{tabular}

\section{DISCCUSION}

Traumas during childbirth are the risk factors for the appearance of torticollis. As a consequence of the trauma, it comes to the tearing or prolongation of the neck muscles, especially when the baby's head is born slowly or very soon, or when the baby's head is snatched by force or violently, or when "pelvic" gets out first then the head. In these cases, it comes to the tearing or breakdown of the muscular fibers as a cause of excessive prolongation, which is not immediately noticeable. Consequences are hematomas within the MSCM that it is formed in the third week of the baby's birth that it can be seen when the baby's neck palpitates $[17,18]$.

Of the total number of infants 160 , the largest number belongs to the age group 0-3 months. As far as gender is concerned, there are 87 cases or $(56.0 \%)$ with female infants attacked by torticollis. As far as it concerns to the number of births, the largest number belongs to the infants born at the first birth, with 40 cases or (47.6\%).

The earliest start of kinesitherapy treatment in the cases diagnosed with torticollis gives better results in the degree of neck's mobility, and a shorter physiotherapeutic treatment is required to achieve normal baby's cervical mobility [19]. After the application of the kinesitherapy, we achieved high results in AEL growth, which were significantly better in the group of age from 0 to 3 months. From the total number, at 152 infants or $(90.5 \%)$ after the treatment, we achieved full amplitude of mobility.

In our study of the total number of examiners, 36 cases or $(22.5 \%)$ had other associated anomalies, such as 13 or $(8.1 \%)$ subluxatio coxae, 12 cases or $(7.5 \%)$ brachial plexus injury, and 11 cases or $(6.9 \%)$ dislocation coxae. Our data correspond to the data of a work done in 1086 babies with torticollis where it was noted that besides cotyledons; there was also a high incidence of podalic presentation (19.5\%), difficult birth or $(56 \%)$, and stomach displacement $(6.81 \%)$. Furthermore, the limitation of the passive neck rotation correlated with the craniofacial asymmetry and irregular shape of the head [20]. From our data, we have come to the conclusion that a small limitation of mobility has left only on some third group infants in the age of groups from 6 to 9 months because the appearance of time for physical treatment has been delayed.

This is also noted in a study involving one hundred and one child (mean age $=4$ months) who were diagnosed with congestive muscular twitching and referred to the physical therapy in the Children's Hospital in the British Columbia (Vancouver, British Columbia, Canada), before they fulfill 2 years old.

Full recovery (full passive motion angle) is achieved for all the children except one. The average duration of treatment was 4.7 months. There was a correlation between the severity of the restriction and the duration of the treatment $(r=0.31)$ [4]. Similar data were also obtained in a prospective study of 45 infants ( 26 boys, 19 girls) with congenital muscle cramps; their average age at the beginning of the therapy was 38.6 days or (15-120 days). The average duration of the treatment was found to be 3.2 1.3 months. All of the patients were treated with intensive, prolonged prophylaxis protocol (with 100\% success). No case was treated surgically. In early-treated muscular-infant babies, there is no room for surgical treatment. This group of patients has been successfully treated using an intensive protocol of passive exercises extension [1].

Clinical characteristics of our patients coincide with those of other works. For example, the patients included in this study were 81 boys and 89 girls, younger than 24 months, who had congenital torticollis. The average age at the time of the diagnosis was 4 months, $54.1 \%$ had the left side of the affected neck, over $90 \%$ had an irregular shape of the head, and $2.4 \%$ had difficulty eating due to the disorder. Plagiocephaly was present in $63.6 \%$ of the patients.

Neck tumefaction was present in $18.2 \%$ of subjects and facial asymmetry in $15.9 \%$. Passive movements were the initial treatment recommended for $65.3 \%$ of the patients. Most of the children achieve a total improvement in symptoms. Nearly $85.5 \%$ have achieved total improvement and $14.5 \%$ have achieved partial improvement or longterm abnormalities [21].

In our study, kinesitherapy, respectively, passive exercises have been applied to all infants and a large number of them have achieved a successfully full recovery. This coincides with the data from the literature. A total of 311 infants were treated consecutively for congenital torticollis during an 8-year period since 1999 until 2003 at the Clinic of Pediatric Neurology at Istanbul's Faculty of Medicine. Istanbul University, Turkey was revised in a retrospectively manner. The average age at diagnosis period was 2.3 months. The included patients in this study were 138 boys and 173 girls. Passive movements were recommended with the initial treatment for all the patients. Nearly 95\% have achieved total improvement and 5\% have achieved partial improvement [22].

We conclude that most of the babies born with muscular torticollis reach the full/complete neck movement. The success rate of conservative treatment it is depended largely on the age of infants when they start with ultrasonography exercises and findings [23]. Furthermore, in a retrospective study of 277 infants with torticollis muscular congenital, $90.6 \%$ of the cases were of average level. Hip dysplasia was directly related with the worst cases of torticollis (10.5\%). Within 12 months, torticollis had been conservatively cured of nearly on approximately $70 \%$ of babies regardless of the severity. Tenotomies were realized or performed in only ten children, eight of whom were first introduced after the age of 12 months. The long-term effects were light and consisted of craniofacial asymmetry, temporary head bend, and mild scoliosis [24].

However, a wide and long-term of research would give a better and clear insight to the effect of treating torticollis infants with the kinesitherapy method. Special researches should be conducted on the role of kinesitherapy and other physical methods with larger samples, with randomized, double-blind and controlled or checked groups. In this way, stratification of the patients in the treatment groups according to the disease, weight, gender, and age would be enabled. Various and diverse researches are needed because all of this cannot be achieved within a single research. However, based on our results and the literature of published work so far in internationally reviewed journals, there is a lot of evidence that supports the recommendation of the kinesitherapy usage for a period of 3 weeks (a period of time that is needed in order for the effect to be shown) because it will have an impact on the effect release of AEL, to the release the muscle of spasms and the improvement of muscle function.

\section{CONCLUSIONS}

From the results of our research, we conclude that kinesiotherapy has a primary and very successful effect on the treatment of the infants with torticollis. Kinesitherapy has been shown to be effective in MSCM extension, growth of the AEL on the neck mobility, and improvement of muscle function. The results of this study will enable therapists to better predict the duration of treatment based on early onset of the physical therapy. 


\section{ACKNOWLEDGMENTS}

We would like to thank all the infants who participated in this study and all their parents who without hesitation helped us by answering the questionnaire.

\section{REFERENCES}

1. Celayir AC. Congenital muscular torticollis: Early and intensive treatment is critical. A prospective study. Pediatr Int 2000;42(5):504-7.

2. Ballock RT, Song KM. The prevalence of nonmuscular causes of torticollis in children. J Pediatr Orthop 1996;16(4):500-4

3. Demirbilek S, Atayurt HF. Congenital muscular torticollis and sternomastoid tumor: Results of nonoperative treatment. J Pediatr Surg 1999;34(4):549-51.

4. Emery C. The determinants of treatment duration for congenital muscular torticollis. Phys Ther 1994;74(10):921-9.

5. Davids JR, Wenger DR, Mubarak SJ. Congenital muscular torticollis: Sequela of intrauterine or perinatal compartment syndrome. J Pediatr Orthop 1993;13(2):141-7.

6. Sönmez K, Türkyilmaz Z, Demirogullari B, Ozen IO, Karabulut R, Bagbanci B, et al. Congenital muscular torticollis in children. ORL J Otorhinolaryngol Relat Spec 2005;67(6):344-7.

7. Freed S, Coulter-O'Berry C. Identification and treatment of congenital muscular torticollis in infants. J Prosthet Orthot 2004;16(4):18-24.

8. Burstein FD. Long-term experience with endoscopic surgical treatment for congenital muscular torticollis in infants and children: A review of 85 cases. Plast Reconstr Surg 2004;114(2):491-3.

9. Karmel-Ross K. Congenital muscular torticollis. In: Campbell SK, Palisano RJ, Linden DW, editors. Physical Therapy for Children. $3^{\text {rd }}$ ed. London: Elsevier Saunders; 2006. p. 359-80.

10. Yu CC, Wong FH, Lo LJ, Chen YR. Craniofacial deformity in patients with uncorrected congenital muscular torticollis: An assessment from three-dimensional computed tomography imaging. Plast Reconstr Surg 2004;113(1):24-33.

11. Buus L, Jensen RB, Pedersen B. Changed incidence of muscular torticollis and craniofacial asymmetry in newborn? A study from the Pediatric Department in Hilleroed Hospital, Denmark, in the years 1994-2000. Forsk Fysioter 2007;5:1-8.
12. Gara E, Haxhiu B, Durguti ZH, Murtezani A. Managing the early phase of rehabilitation after an ischemic cerebrovascular accident. Int J Pharm Pharm Sci 2017;9(6):194-7.

13. Stellwagen L, Hubbard E, Chambers C, Jones KL. Torticollis, facial asymmetry and plagiocephaly in normal newborns. Arch Dis Child 2008;93(10):827-31.

14. Rogers GF, Oh AK, Mulliken JB. The role of congenital muscular torticollis in the development of deformational plagiocephaly. Plast Reconstr Surg 2009;123(2):643-52

15. Ibraimi Z, Shehi A, Murtezani A, Haliti F. The possibility of development of antibiotic resistance from massive and uncontrolled use of sulfonamides in milk. Int J Pharm Pharm Sci 2017;9(4):207-11.

16. Ohman A, Nilsson S, Lagerkvist AL, Beckung E. Are infants with torticollis at risk of a delay in early motor milestones compared with a control group of healthy infants? Dev Med Child Neurol 2009;51(7):545-50.

17. Ohman AM, Nilsson S, Beckung ER. Validity and reliability of the muscle function scale, aimed to assess the lateral flexors of the neck in infants. Physiother Theory Pract 2009;25(2):129-37.

18. Kaplan SL, Coulter C, Fetters L. Physical therapy management of congenital muscular torticollis: An evidence-based clinical practice guideline: From the Section on Pediatrics of the American Physical Therapy Association. Pediatr Phys Ther 2013;25(4):348-94.

19. Matin A, Islam R, Roy RR, Rakshit BK, Khan R. Management of congenital muscular torticollis under one year of age. J Shaheed Suhrawardy Med Coll 2009;1(2):1-4.

20. Cheng JC, Tang SP, Chen TM, Wong MW, Wong EM. The clinical presentation and outcome of treatment of congenital muscular torticollis in infants - A study of 1,086 cases. J Pediatr Surg 2000;35(7):1091-6.

21. Wei JL, Schwartz KM, Weaver AL, Orvidas LJ. Pseudotumor of infancy and congenital muscular torticollis: 170 cases. Laryngoscope 2001;111:688-95.

22. Tatli B, Aydinli N, Çalıskan M, Ozmen M, Bılır F, Acar G. Congenital muscular torticollis: Evaluation and classification. Pediatr Neurol 2006;34(1):141-4.

23. Do TT. Congenital muscular torticollis: Current concepts and review of treatment. Curr Opin Pediatr 2006;18(1):26-9.

24. Binder H, Eng GD, Gaiser JF, Koch B. Congenital muscular torticollis: Results of conservative management with long-term follow-up in 85 cases. Arch Phys Med Rehabil 1987;68(4):222-5. 